\title{
PENGARUH RASA PERCAYA DIRI DAN INTENSITAS INTERAKSI SOSIAL TERHADAP PENYESUAIAN DIRI ANAK JALANAN DI KOTA MADIUN
}

\begin{abstract}
Desti Lestari * Muh. Chotim **
Abstrak

Penelitian ini bertujuan untuk mengetahui pengaruh rasa percaya diri dan intensitas interaksi sosial terhadap penyesuaian diri anak jalanan di Kota Madiun.

Penentuan sampel pada penelitian ini menggunakan populasi sensus, yaitu mengambil seluruh data anak jalanan yang ada di kota madiun. Pengambilan sampel seluruhnya sebanyak 21 anak atau $100 \%$ dari jumlah populasi yang berjumlah 21 anak. Pengumpulan data yang dilakukan dalam penelitian ini adalah menggunakan angket. Dalam menganalisa data digunakan teknik analisa regresi korelasi linier multiple untuk menguji ada tidaknya hubungan positif yang signifikan antara rasa percaya diri, intensitas interaksi sosial, dan penyesuaian diri.

Hasil penelitian ini menunjukkan hasil yang signifikan antara rasa percaya diri $\left(\mathrm{X}_{1}\right)$ dan Intensitas interaksi sosial $\left(\mathrm{X}_{2}\right)$ terhadap penyesuaian diri $(\mathrm{Y})$. Hasil analisa data tentang pengaruh rasa percaya diri $\left(\mathrm{X}_{1}\right)$ terhadap penyesuaian diri $(\mathrm{Y})$ menunjukkan harga nilai konstan $(\mathrm{a})=6.430$ dan beta $=0.617$ serta $\mathrm{t}$-hitung $=$ 4.229 dan tingkat Sig $=0,001$. Untuk pola rasa percaya diri Sig 0,001 lebih kecil dari taraf signifikasi 5\%, untuk $\mathrm{N}$ sebanyak 21. Jadi hipotesis yang berbunyi : terdapat pengaruh antara rasa percaya diri terhadap penyesuaian diri dinyatakan diterima. Hasil analisa data tentang pengaruh intensitas interaksi sosial $\left(\mathrm{X}_{2}\right)$ terhadap penyesuaian diri (Y) menunjukkan harga nilai konstan (a) $=6.430$ dan beta $=0.378$ serta t-hitung $=2.592$ dan tingkat $\mathrm{Sig}=0.018$. Untuk intensitas interaksi sosial nilai Sig 0,018 lebih kecil dari pada taraf signifikasi 5\%, untuk N sebanyak 21. Jadi hipotesis yang berbunyi : terdapat pengaruh antara intensitas interaksi sosial terhadap penyesuaian diri dinyatakan diterima. Dari hasil uji $\mathrm{F}$ menggunakan anova tentang pengaruh rasa percaya diri dan intensitas interaksi sosial terhadap penyesuaian diri anak jalanan menunjukkan bahwa Freg $=16,123$ $>$ Ftab $=3,47$ dengan taraf signifikan 5\%. Jadi hipotesis yang berbunyi: terdapat pengaruh secara simultan rasa percaya diri dan intensitas interaksi sosial terhadap penyesuaian diri dinyatakan diterima. Penelitian ini dalam penghitungannya menggunakan program SPSS (Statistical Product and Service Solution) 16.
\end{abstract}

Dari hasil penelitian ini dapat disimpulkan bahwa ada pengaruh rasa percaya diri dan intensitas interaksi sosial terhadap penyesuaian diri anak jalanan di kota Madiun.

Kata kunci : Rasa Percaya Diri, Intensitas Interaksi Sosial, Penyesuaian Diri.

* Desti Lestari adalah Mahasiswa Program Studi Bimbingan dan Konseling Fakultas Ilmu Pendidikan IKIP PGRI Madiun.

** Muh. Chotim adalah Dosen Program Studi Bimbingan dan Konseling Fakultas Ilmu Pendidikan IKIP PGRI Madiun. 


\section{Pendahuluan}

Anak jalanan adalah anak-anak yang masih dibawah umur dengan menghabiskan seluruh atau sebagian besar waktunya di jalanan, berkeliaran di dalam kota. Anak jalanan harus bertahan hidup dengan cara-cara yang secara sosial kurang atau bahkan tidak dapat diterima masyarakat umum sekadar untuk menghilangkan rasa lapar dan keterpaksaan untuk membantu keluarganya. Anak jalanan bukanlah kelompok yang homogen, tetapi juga cukup beragam, dan dapat dibedakan atas dasar pekerjaannya, hubungan dengan orang tua atau orang dewasa terdekat, waktu dan jenis kegiatannya di jalanan, serta jenis kelaminnya (Farid, 1998).

Keadaan kota Madiun yang berkembang menjadi kota perekonomian, yang sudah banyak dibangun pusat-pusat ekonomi, sehingga menjadi jujugan anak-anak jalanan yang berasal dari luar kota untuk mengais rejeki. Selain itu juga kebutuhan ekonomi yang tinggi membuat anak dari dalam kota harus ikut serta membantu orang tuanya, dengan terjun ke jalan-jalan untuk mengemis, menjadi loper koran ataupun mengamen. Selain itu juga dapat terjadi karena keadaan keluarga, sehingga membuat anak kurang diperhatikan, baik dalam pendidikan, kasih sayang, membuat anak kehilangan hak untuk bermain, bergembira, bermasyarakat, atau bahkan mengakibatkan anak-anak dianiaya fisik maupun mental oleh keluarga. Dengan adanya Perda Kota Madiun No. 8 Tahun 2010 mengenai Penyelengaraan Ketentraman dan Ketertiban Umum yang melarang anak jalanan untuk mengamen, meminta-meminta, dan berjualan di traffic light, anak jalanan di Kota madiun banyak berkeliaran di perumahan - perumahan penduduk dan di tempat-tempat keramaian seperti Alun-alun Madiun dan Taman Bantaran Kali Madiun, dan tempat keramaian lainnya.

Anak jalanan, tetap seperti kebanyakan anak pada umumnya, terlahir dengan mempunyai bakat dan minat, walaupun mereka tidak menyadari dan mengembangkan karena keadaan yang dialami. Serta mempunyai keinginan atau cita-cita yang begitu besar untuk dirinya. Cita-cita besar yang lebih baik kelak, walaupun mereka menyadari statusnya. Dan diharapkan rasa percaya 
diri selalu ditanamkan kepada masing-masing pribadi anak jalanan agar mereka selalu yakin pada kemampuannya.

Intensitas Interaksi sosial individu dapat berkembang karena adanya dorongan rasa ingin tahu terhadap segala sesuatu yang ada di lingkungan sekitarnya yaitu orang tua, teman sebaya dan masyarakat. Anak jalanan pun harus juga berinteraksi dengan lingkungan sosialnya. Dengan melakukan interaksi itu diharapkan agar masyarakat tidak memandang negatif mereka dan dapat menerima status mereka, serta menganggap mereka seperti kebanyakan anak pada umumnya. Diharapkan pula dengan melakukan interaksi sosial dengan masyarakat sekitar, anak jalanan dapat terbiasa dengan etika ataupun norma yang berlaku, agar tingkah laku mereka dapat terkendali. Dengan berinteraksi sosial yang baik diharapkan pula anak jalanan mampu melakukan penyesuaian diri. Penyesuaian diri terjadi dengan adanya keselarasan antara individu dengan dirinya sendiri dan lingkungan di sekitarnya. Mampu menerima keadaan diri sendiri di tengah-tengah masyarakat dan memahami apa yang menjadi kebutuhan dan menyesuaikannya di dalam masyarakat.

Dengan penuh rasa percaya diri, yakin terhadap kemampuan yang dimiliki dan berinteraksi sosial dengan individu-individu lain di sekitar dalam berkomunikasi, bergaul, bersikap dan bertingkah laku dengan baik, serta menaati peraturan atau norma-norma sosial, serta bagaimana mereka melakukan interaksi sosial dan seberapa intensitas mereka untuk berinteraksi sosial dengan masyarakat sekitar, dengan gambaran keadaan yang seperti itu anak jalanan yang tergolong masih dibawah umur dengan segala kondisi yang berbeda dengan kebanyakan anak-anak yang lainnya di harapkan mampu melakukan penyesuaian diri baik dengan diri sendiri maupun lingkungan sosial dengan baik serta dapat di terima dan dipandang positif oleh masyarakat.

Berdasarkan realita-realita tersebut peneliti tertarik untuk melakukan penelitian dengan judul "Pengaruh Rasa Percaya Diri Dan Intensitas Interaksi Sosial Terhadap Penyesuaian Diri Anak Jalanan di Kota Madiun”. 


\section{Metode}

Penelitian ini menggunakan metode ex post facto. Menurut Suharsimi Arikunto (2010: 203) metode ex post facto yaitu suatu penelitian ilmiah yang penelitinya tidak dapat secara langsung memanipulasi dan mengendalikan satu atau lebih variabel bebas serta mengamati variabel terikat untuk melihat perbedaan yang sesuai dengan manipulasi variabel tersebut.

Populasi dalam penelitian ini adalah anak jalanan yang terdata di Rumah Singgah Al Gheins dan anak jalanan yang di temui di tempat-tempat umum dengan jumlah 21 anak. Dalam penelitian ini peneliti mempergunakan teknik penarikan sampel populasi dan dalam penelitian ini hanya sebanyak 21 anak saja sebagai subjek penelitian, maka peneliti menggunakan teknik seperti dikatakan Suharsimi Arikunto (2010:134), jika subjeknya kurang dari 100 orang maka lebih baik diambil semua sebagai populasi yakni sebanyak 21 anak, dalam istilah lain juga dikenal dengan istilah sampel sensus.

Dalam penelitian ini peneliti menggunakan teknik angket dalam mengumpulkan data dari anak-anak jalanan. Menurut Suharsimi Arikunto (2010: 194) angket atau kuesioner adalah sejumlah pertanyaan tertulis yang digunakan untuk memperoleh informasi dari responden dalam arti laporan tentang pribadi, atau hal-hal yang ia ketahui. Angket atau kuesioner dalam penelitian ini digunakan untuk memperoleh data tentang rasa percaya diri, intensitas interaksi sosial dan penyesuaian diri. Angket yang digunakan dalam penelitian ini adalah angket langsung dan tertutup. Angket langsung yaitu responden menjawab tentang dirinya sendiri. Angket tertutup adalah sudah disediakannya jawaban sehingga responden tinggal memilih (Suharsimi Arikunto, 2010:129).

Angket disusun dalam bentuk 4 alternatif jawaban, yaitu: (A) selalu, (B) sering, (C) kadang-kadang, (D) tidak pernah. Jumlah item yang disediakan adalah 18 item yang disusun sendiri oleh peneliti. Cara pemberian skor hasil isian angket ini mengacu pada skali likert. Sugiyono (2011:93) berpendapat skala likert digunakan untuk mengukur sikap, pendapat, dan persepsi sesorang atau sekelompok orang tentang fenomena sosial. 
Teknik analisa yang digunakan adalah Analisa Regresi Korelasi Linier Multiple dengan rumus sebagai berikut (Ridwan \& Engkos, 2008):

[. $X_{2}, Y=\sqrt{\frac{r^{2} X_{1}, Y+r^{2} X_{2}, Y-2\left(X_{1}, Y\right) \cdot\left(r X_{2}, Y\right) \cdot\left(r X_{1}, X_{2}\right)}{1-r^{2} X_{1} X_{2}}}$

Keterangan:

$\mathrm{Rx}_{1} \cdot \mathrm{X}_{2} \cdot \mathrm{Y}=$ angka korelasi antara $\mathrm{x}_{1}$ dengan $\mathrm{x}_{2}$ dan $\mathrm{Y}$

$\mathrm{rx}_{1} \cdot \mathrm{x}_{2}=$ angka korelasi antara $\mathrm{x}_{1}$ dengan $\mathrm{x}_{2}$

$\mathrm{rx}_{2} \cdot \mathrm{Y}=$ angka korelasi antara $\mathrm{x}_{2}$ dengan $\mathrm{Y}$

$1=$ angka tetap

\section{Hasil}

A. Deskripsi Data

Hasil analisis ini didasarkan pada perhitungan menggunakan program SPSS (Statistical Product and Service Solution) 16 yang dapat di deskripsikan sebagai berikut:

a. Data Rasa Percaya Diri diperoleh hasil hitung mean $=53,19$, median $=$ 54 , modus $=50^{\mathrm{a}}$, dan standart deviasi $=4,214$. Nilai tertinggi $=61$, nilai terendah $=45$, dengan demikian rentang kelas $61-45=16$. Selanjutnya banyaknya kelas interval $=4$, maka dapat diperoleh panjang kelas $=4$.

Tabel 3.1 Distribusi Frekuensi Rasa Percaya Diri

\begin{tabular}{|c|c|}
\hline Interval & Frekuensi \\
\hline $57-61$ & 4 \\
\hline $53-56$ & 7 \\
\hline $49-52$ & 7 \\
\hline $45-48$ & 3 \\
\hline JUMLAH & $\mathbf{2 1}$ \\
\hline
\end{tabular}

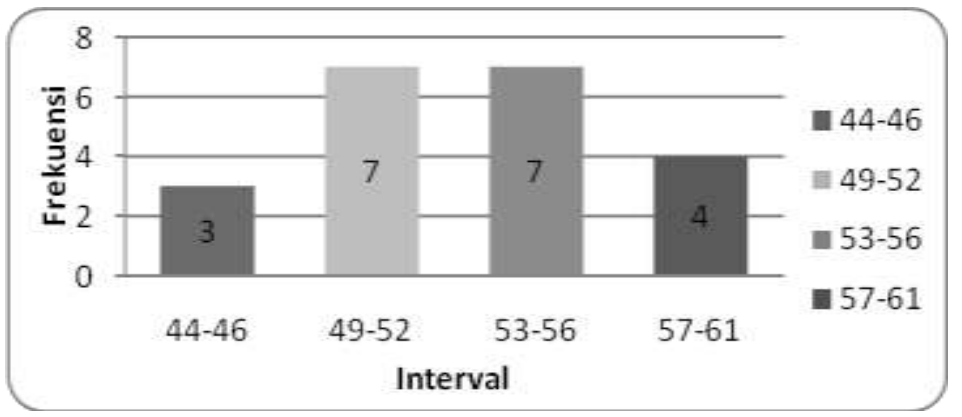

Grafik. 3.1 Frekuensi Rasa Percaya Diri 
b. Data untuk Intensitas interaksi sosial diperoleh hasil hitung mean = 52.09 , median $=54$, modus $=54^{\mathrm{a}}$, dan standart deviasi $=4.795$. Nilai tertinggi $=59$, nilai terendah $=42$, dengan demikian rentang kelas 59 $-42=17$. Selanjutnya banyaknya kelas interval $=4$, maka dapat diperoleh panjang kelas $=4$.

Tabel 3.2 Distribusi Frekuensi Intensitas Interaksi Sosial.

\begin{tabular}{|c|c|}
\hline Interval & Frekuensi \\
\hline $56-59$ & 8 \\
\hline $51-55$ & 6 \\
\hline $46-50$ & 4 \\
\hline $42-45$ & 3 \\
\hline JUMLAH & $\mathbf{2 1}$ \\
\hline
\end{tabular}

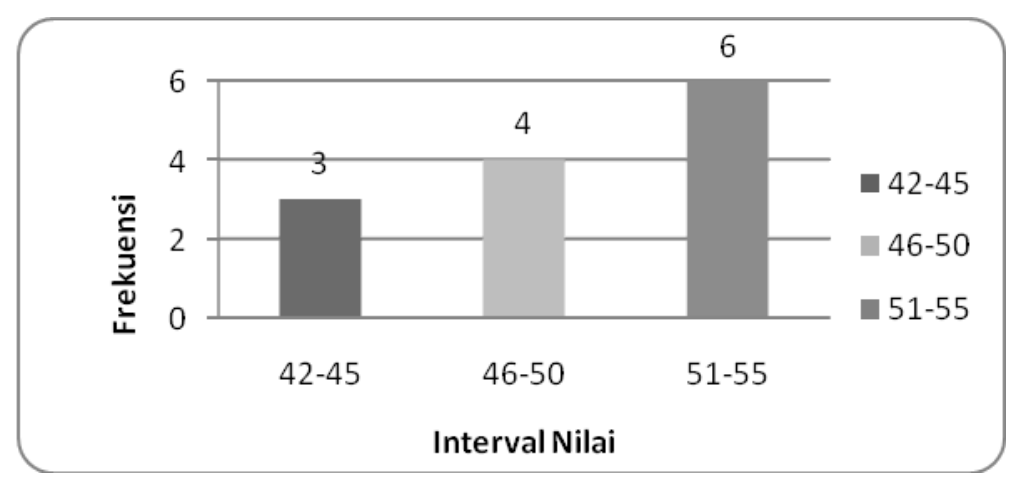

Grafik 3.2 Frekuensi Intensitas Interaksi Sosial

c. Data untuk penyesuain diri diperoleh hasil hitung mean $=53,19$, median $=53$, modus $=47^{\mathrm{a}}$, dan standart deviasi $=3.932$. Nilai tertinggi $=61$, nilai terendah $=47$, dengan demikian rentang kelas 61$47=14$. Selanjutnya banyaknya kelas iterval $=3$, maka dapat diperoleh panjang kelas $=5$.

Tabel 3.3. Distribusi Frekuensi Penyesuain Diri

\begin{tabular}{|c|c|}
\hline Interval & Frekuensi \\
\hline $57-61$ & 5 \\
\hline $52-56$ & 9 \\
\hline $47-51$ & 7 \\
\hline JUMLAH & $\mathbf{2 1}$ \\
\hline
\end{tabular}




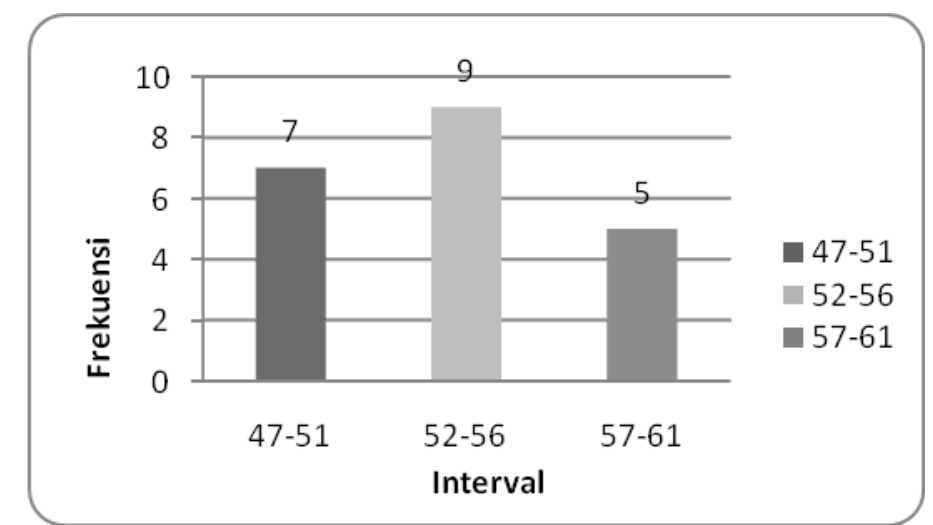

Grafik 3.3 Frekuensi Penyesuaian Diri

B. Hasil Analisis Data

Hasil perhitungan menggunakan program SPSS (Statistical Product and Service Solution) 16 dengan hasil sebagai berikut:

a. Hasil uji t tentang pengaruh rasa percaya diri terhadap penyesuaian diri dengan hasil nilai konstan $(\mathrm{a})=6.430$ dan beta $=0.617$ serta $\mathrm{t}$ hitung $=4.229$ dan tingkat $\operatorname{Sig}=0,001$. Untuk pola rasa percaya diri Sig lebih kecil dari taraf signifikasi 5\% oleh karena itu rasa percaya diri dinyatakan berpengaruh terhadap penyesuaian diri.

b. Hasil uji t tentang pengaruh intensitas interaksi sosial terhadap penyesuaian diri dengan hasil nilai konstan (a) $=6.430$ dan beta $=$ 0.378 serta t-hitung $=2.592$ dan tingkat $\operatorname{Sig}=0.018$. Untuk intensitas interaksi sosial nilai Sig lebih kecil dari pada taraf signifikasi 5\%, oleh karena itu intensitas interaksi sosial dinyatakan berpengaruh terhadap penyesuaian diri.

c. Hasil uji Anova diperoleh adalah nilai $\mathrm{F}=16.123$ dengan tingkat sig $=$ 0,00. Oleh karena probabilita Sig lebih kecil dari 0,05 ini berarti $\mathrm{H}_{\mathrm{o}}$ ditolak sehingga rasa percaya diri dan intensitas interaksi sosial berpengaruh terhadap penyesuaian diri.

d. Hasil regresi dengan model summary, Pada variabel rasa percaya diri dan intensitas interaksi sosial terhadap penyesuaian diri menunjukkan nilal $\mathrm{R}=0.801$ dengan koefisien determinasi $\mathrm{R}$-square sebesar 0.642. Hal ini menunjukkan pengertian bahwa penyesuaian diri (Y) 
dipengaruhi sebesar $64,2 \%$ oleh variabel rasa percaya diri $\left(\mathrm{X}_{1}\right)$ dan intensitas interaksi sosial $\left(\mathrm{X}_{2}\right)$, sedangkan sisanya $(100 \%-64,2 \%=$ $35,8 \%$ ) dipengaruhi oleh variabel lainnya.

Berdasarkan analisis data di atas, maka simpulan hipotesis dalam penelitian ini adalah:

a. Hipotesis yang berbunyi: Ada pengaruh rasa percaya diri terhadap penyesuaian diri anak jalanan di Kota Madiun, dinyatakan diterima.

b. Hipotesis yang berbunyi: Ada pengaruh intensitas interaksi sosial terhadap penyesuaian diri anak jalanan di Kota Madiun, dinyatakan diterima.

c. Hipotesis yang berbunyi: Ada pengaruh secara simultan rasa percaya diri dan intensitas interaksi sosial terhadap penyesuaian diri anak jalanan di Kota Madiun, dinyatakan diterima.

\section{Simpulan}

Berdasarkan analisis data dari penelitian yang telah dilaksanakan diperoleh beberapa simpulan sebagai berikut:

1. Ada Pengaruh Rasa Percaya Diri Terhadap Penyesuaian Diri Anak Jalanan di Kota Madiun.

2. Ada Pengaruh Intensitas Interaksi Sosial Terhadap Penyesuaian Diri Anak Jalanan di Kota Madiun

3. Ada Pengaruh Secara Simultan Rasa Percaya Diri Dan Intensitas Interaksi Sosial Terhadap Penyesuaian Diri Anak Jalanan di Kota Madiun.

Berdasarkan penelitian yang dilakukan dikemukakan beberapa saran berikut: a. Konselor, Konselor tetap harus memperhatikan masalah sosial yang ada di sekitarnya. Kemungkinan anak didiknya bekerja di jalanan setelah melaksanakan sekolah yang membutuhkan perhatian khusus; b. Orang tua, Orang tua harus selalu memperhatikan segala kegiatan anaknya, walaupun harus memperlibatkan anak untuk membantu mencari nafkah, selalu senantiasa 
memberikan segala hak-hak yang harus diterima anaknya, salah satunya adalah pendidikan; c. Anak Jalanan, anak jalanan tetap memiliki rasa kepedulian sosial, dengan selalu berinteraksi dengan individu lain di lingkungan sekitarnya agar tidak dipandang negatif oleh masyarakat luas dan tetap melaksanakan pendidikannya, agar dapat melangsungkan kehidupan selanjutnya lebih baik; d. Masyarakat, anak jalanan tetaplah bagian dari masyarakat, dalam berinteraksinya untuk melakukan penyesuaian diri dalam masyarakat tersebut. Walaupun terkadang anak jalanan sedikit menyimpang dari norma dan nilai sosial, sebagai masyarakat yang baik harus tetap mengingatkan dan berusaha memperbaiki.

\section{DAFTAR PUSTAKA}

Bagong Suyanto. 2010. Masalah Sosial Anak. Jakarta: kencana Prenada Media Group.

Perda Kota Madiun No. 8 Tahun 2010. Penyelenggaraan Ketentraman dan Ketertiban Umum. (Online), http//jdih.jatimprov.go.id/kotamadiun/, di unduh pada tanggal 3 Maret 2012).

Ridwan dan Engkos Achmad Kuncoro. 2008. Cara Menggunakan dan Memakai Analisis Jalur. Bandung: Alfabeta.

Sugiyono. 2011. Metode Penelitian Kuantitatif, Kualitatif dan R\&D. Bandung: Alfabeta

Suharsimi Arikunto. 2010. Prosedur Penelitian. Jakarta: Rineka Cipta. 